\title{
Expression of Platelet-Derived Growth Factor-AA is Associated with Tumor Progression in Osteosarcoma
}

Irene Sulzbacher, M.D., Peter Birner, M.D., Klemens Trieb, M.D., Margit Träxler, Susanna Lang, M.D., Andreas Chott, M.D.

Clinical Institute of Pathology (IS, PB, MT, SL, AC) and Department of Orthopedics (KT), University of Vienna Medical School, Vienna, Austria

Platelet-derived growth factors are secreted by mesenchymal cells. The homodimer plateletderived growth factor-AA especially stimulates bone cells through interaction with the plateletderived growth factor- $\alpha$ receptor homodimer. In this study we wanted to determine the expression of the receptor and its ligand in human osteosarcomas and to correlate the expression of platelet-derived growth factor-AA and - $\alpha$ receptor with clinicopathological parameters. Fifty-seven osteosarcomas were immunohistochemically analyzed for expression of platelet-derived growth factor-AA and plateletderived growth factor- $\alpha$ receptor. Spearman's correlation coefficient revealed a strong correlation between the expression of platelet-derived growth factor-AA and platelet-derived growth factor- $\alpha$ receptor $(r=0.867)$. No differences were observed relative to gender, age, tumor stage, tumor location, and response to neoadjuvant chemotherapy between high or low platelet-derived growth factor-AA and platelet-derived growth factor- $\alpha$ receptor expression. High platelet-derived growth factor-AA expression correlated with tumor progression in univariate analysis $(P=.0415$; log-rank test $)$, whereas platelet-derived growth factor- $\alpha$ receptor expression showed a trend toward a shorter disease-free survival, which failed to reach significance ( $P=.0627$, log-rank test). In multivariate analysis, platelet-derived growth factor-AA expression remained a significant independent predictor of tumor progression $(P=.021$, Cox regression). Immunohistochemical analysis of platelet-derived growth factor-AA expression in osteosarcoma may be a useful marker of prognosis

Copyright () 2003 by The United States and Canadian Academy of Pathology, Inc.

VOL. 16, NO. 1, P. 66, 2003 Printed in the U.S.A.

Date of acceptance: October 7, 2002.

Address reprint requests to: Irene Sulzbacher, M.D., Clinical Institute of Pathology, Vienna General Hospital, Währinger Gürtel 18-20, A-1090 Vienna, Austria; e-mail: irene.sulzbacher@akh-wien.ac.at; fax: 43-1-4053402.

DOI: 10.1097/01.MP.0000043522.76788.0A and may be considered as a possible target for novel therapeutic strategies.

KEY WORDS: Osteosarcoma, PDGF-AA, PDGF- $\alpha$ receptor, Prognosis.

Mod Pathol 2003;16(1):66-71

Osteosarcoma, a frequent tumor of childhood and adolescence, represents the most common primary malignant bone tumor (1). Despite aggressive treatment modalities such as adjuvant chemotherapy or wide tumor resection, the frequency of metastases, especially in the lung, is high, occurring in approximately $40-50 \%$ of patients. Therefore, osteosarcoma remains a major cause of fatal outcome (2).

Tumor metastasis is a multistep process that involves a variety of tumor cell-host interactions. One major step is neovascularization, a process in which angiogenic factors such as vascular endothelial growth factor (VEGF) are essential. Expression of VEGF is well documented in osteosarcoma $(3,4)$, and its expression is positively influenced by the inducing agent platelet-derived growth factors (PDGFs; 5). These proteins exist of two different polypeptide chains, which can combine to form three different disulfide-linked dimers, AA, BB, or $A B$. Recently, PDGF-C and PDGF-D, two new PDGFs, were discovered; these form a separate PDGF subfamily (6). They exert their biological function by binding to three different receptor dimers, two homodimers $(\alpha \alpha, \beta \beta)$, and one heterodimer $(\alpha, \beta ; 7,8)$. Mesenchymal cells especially are the target of these growth factors.

The homodimer PDGF AA and its receptor are expressed by human osteoblasts, which has been documented in in vivo studies $(9,10)$. In our previous study we have demonstrated the expression of the homodimer PDGF-AA and its receptor, PDGF- $\alpha$ receptor, in human osteosarcomas (11). We documented an overexpression of PDGF-AA and PDGF- $\alpha$ receptor in osteosarcomas compared with the case in benign human osteoblastomas, and a strong correlation was detected between li- 
gand and receptor expression in osteosarcomas. Therefore, we concluded that an autocrine and/or paracrine loop may be responsible for growth stimulation via receptor-ligand interaction.

Because tumor growth is stimulated indirectly by PDGFs inducing angiogenesis as well as the direct receptor-ligand interaction in tumor cells, we investigated the expression of PDGF-AA and PDGF- $\alpha$ receptor in 57 human osteosarcomas and compared the results with clinicopathological data to elucidate the possible role of PDGF expression as a prognostic marker for osteosarcoma patients.

\section{MATERIALS AND METHODS}

\section{Material}

Fifty-seven patients with osteosarcoma of bone were selected from the files of the Department of Pathology at the Vienna General Hospital. All cases were reviewed to confirm the diagnosis, and a paraffin block of osteosarcoma biopsy material before chemotherapy and surgery was selected for immunohistochemical studies. The osteosarcoma specimens were intramedullary high-grade tumors and consisted of the following types: 32 osteoblastic osteosarcomas, 15 chondroblastic osteosarcomas, 6 anaplastic osteosarcomas, 2 fibroblastic osteosarcomas, and 1 telangiectatic and 1 small-cell osteosarcoma.

The patients underwent treatment between 1992 and 1999 at the Department of Orthopedics at the Vienna General Hospital. All patients were initially treated for primary tumors.

As controls, five specimens with bone remodeling sites were examined and comprised bone material close to areas with osteoarthritis.

\section{Immunohistochemistry}

Freshly cut serial sections were used for immunohistochemical staining for PDGF-AA and PDGF- $\alpha$ receptor, respectively, and corresponding sections were stained with hematoxylin and eosin.

Immunohistochemical studies were done on paraffin sections using a polyclonal rabbit antibody against human PDGF-AA (N-30, Santa Cruz Biotechnology, Santa Cruz, CA; 1:50) raised against a peptide corresponding to amino acids 182-211. After incubation at room temperature for 1 hour, the secondary biotinylated goat anti-rabbit IgG antibody (1:100) was applied for 30 minutes, followed by incubation with the avidin-biotin complex with alkaline phosphatase (ABC-AP Kit, Vector Laboratories, Burlingame, CA). The reaction was developed in the presence of fast red chromogen system (Coulter Immunotech, Marseille, France). The antibody used for the detection of PDGF- $\alpha$ receptor (C-20, Santa Cruz Biotechnology; 1:40) was a rabbit polyclonal antibody raised against a peptide corresponding to amino acids 1065-1084 mapping within the carboxy terminal domain of PDGF- $\alpha$ receptor. Sections were pretreated by microwaving in citrate buffer ( $\mathrm{pH}$ 6.0) twice for 5 minutes each at $600 \mathrm{~W}$. The sections were then incubated with the antibody for 1 hour, followed by incubation with biotinylated goat anti-rabbit IgG as a secondary antibody (1:100). The procedure was completed as described above.

For both antibodies, nonspecific reactivity was assessed by omission of the primary antibody, and the specificity was confirmed in tumor sections as well as in control tissue by preabsorption of the antisera with blocking peptides supplied by the manufacturer. Equimolar concentrations of antibody and blocking peptides were incubated in $1 \%$ Tris-PBS for 1 hour at room temperature. Staining for PDGF-AA and for PDGF- $\alpha$ receptor was completely abolished by this procedure.

Immunoreactivity was assessed at high-power magnification in five to eight microscopic fields that showed maximum reactivity, and it was expressed as the percentage of positive cells per 500 tumor cells.

\section{Statistical Analysis}

The Kruskal-Wallis test, Mann-Whitney test, and Spearman's correlation coefficient were used as appropriate. Overall survival was defined as time from the day of primary surgery until the death of the patient. Data concerning patients who survived until the end of the observation period were censored at their last follow-up visit. Death from a cause other than osteosarcoma was considered as a censoring event. Disease-free survival was defined from the end of primary therapy until the first evidence of progression of disease. Mean values of PDGF-AA and PDGF- $\alpha$ receptor expression were used as cutoff levels for statistical survival analysis. Univariate analysis of overall survival and diseasefree survival was performed as outlined by Kaplan and Meier (12). The Cox proportional hazards model was used for multivariate analysis.

A two-tailed $P$ value of $\leq .05$ was considered significant. All statistical analysis was performed using the SPSS software (RE 10.0; SPSS, Inc., Chicago, IL).

\section{RESULTS}

\section{Clinicopathological Data of Osteosarcoma Patients}

The age of the 57 patients ranged from 6 to 65 years (mean, $21 \mathrm{y}$ ). Thirty-nine patients were under the age of 20 years. The peak incidence of osteosar- 
comas was registered in the second decade of life. Thirty-six patients were men, and 21 were women.

Four tumors were located in the pelvis, including 2 in the sacrum and 2 in the ilium. All other tumors were located in the extremities, including 28 in the femur, 18 in the tibia, 2 in the fibula, 4 in the humerus, and 1 in the intermediate cuneiform bone. The treatment consisted of preoperative multiagent chemotherapy according to two different protocols of the Cooperative Osteosarcoma Study trials (COSS 86c, $n=24$; COSS 96, $n=32$; 13), followed by surgical resection with wide resection margins in all cases. One patient did not receive preoperative chemotherapy.

At the time of surgery, 4 tumors were confined to bone, and 53 had invaded the adjacent soft tissue. The resected specimens were analyzed histologically for response to chemotherapy according to the criteria of Salzer-Kuntschik et al. (14). This system is based on the proportion of viable tumor tissue evaluated on the cross-section of the tumor's largest diameter. Less than $10 \%$ of viable tumor tissue is considered a good response, whereas $>10 \%$ of viable tumor cells indicates a nonresponder; 24 cases were classified as responders and 32 as nonresponders.

The duration of follow-up for survivors ranged from 3.5 months to 8.5 years (median, 3.4 y) from the date of surgery. During this period, 20 patients developed metastasis exclusively in the lung, and three patients had a local recurrence. Thirteen patients died of tumor progression. The 5-year survival rate was $65.16 \%$, and mean overall survival time was 6.4 years (SD, 0.48).

\section{Immunohistochemistry}

In the control material, activated cuboidal osteoblasts of remodeling sites stained strongly for PDGF-AA and PDGF- $\alpha$ receptor, as already demonstrated in former studies $(10,11)$. Immunohistochemistry allowed protein detection in the cyto- plasm for both proteins, and for the receptor, a faint membrane labeling was sometimes detected, although most of the protein accumulated in the cytoplasm. In serial sections, a positive signal in the same cells was widely detectable (not shown).

Osteosarcoma cells stained for both antibodies with positive signals in different tumor cell types such as mononuclear tumor cells, bizarre giant cells, or cells of chondroid differentiated areas (Fig. 1). PDGF-AA labeling ranged from 0 to $80 \%$ (mean, $21 \%$; SD, $21.25 \%$ ), and 7 osteosarcomas were completely negative. In 10 tumors, the protein expression was found only in one area; the other specimens showed a widely distributed positivity.

PDGF- $\alpha$ receptor staining also ranged from 0 to $80 \%$ (mean, $34 \%$; SD, $25.41 \%$ ), but only one osteosarcoma did not show a positive signal. This tumor was also PDGF-AA negative. The receptor expression was multifocal in all osteosarcomas.

As in control tissue, co-expression of both proteins was detectable in serial sections. Spearman's correlation coefficient (two-tailed) revealed a significant correlation between the expression of PDGF-AA and PDGF- $\alpha$ receptor $(r=0.867, P<$ $0.001)$.

\section{Correlation with Clinicopathological Data; \\ Overall and Disease-Free Survival Analysis}

No correlation was found between PDGF-AA and PDGF- $\alpha$ receptor expression and patient's age $(\leq 20$ versus $>20$ years), gender, tumor extension based on Enneking's staging system (intracompartmental lesion versus extracompartmental lesion), location (upper extremities versus lower extremities versus trunk), and response to chemotherapy (responder versus non-responder; $P>.05$, Kruskal-Wallis and Mann-Whitney test, respectively) with the exception of a correlation between patient's age and PDGF- $\alpha$ receptor expression ( $P=.039$, MannWhitney test), which revealed higher protein expression in patients $>20$ years of age (mean;
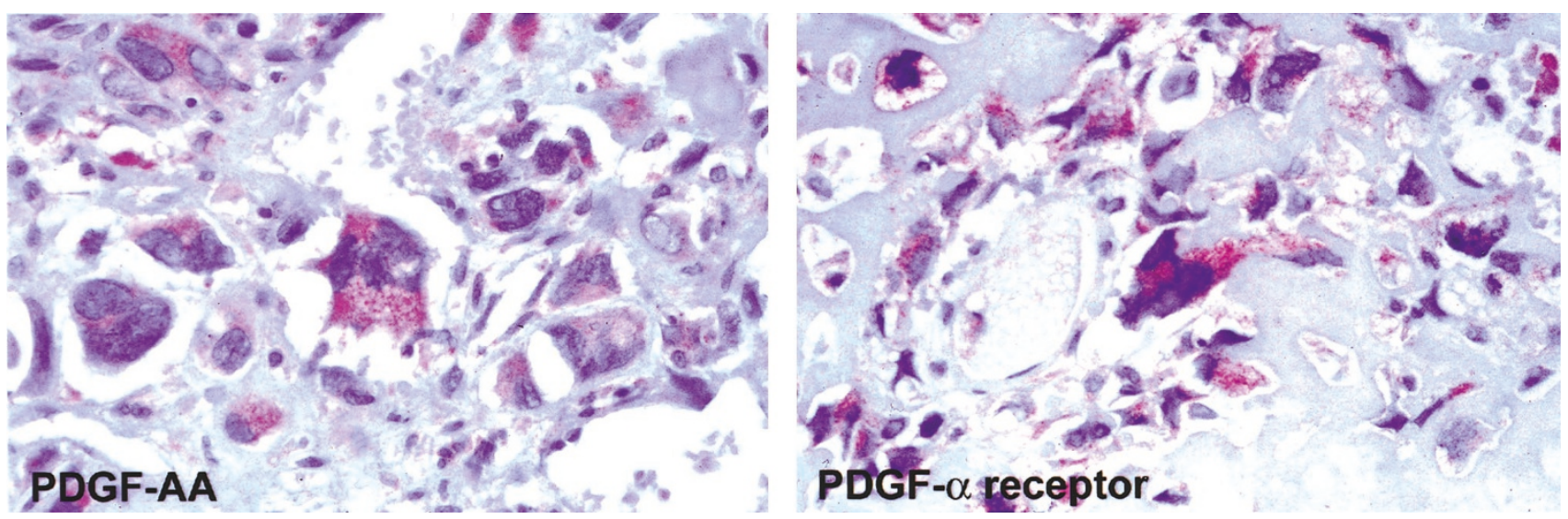

FIGURE 1. Immunohistochemical staining of PDGF-AA and PDGF- $\alpha$ receptor in an example of osteoblastic osteosarcoma (magnification, 400 $\times$ ). 
47.50\%) compared with patients who were $\leq 20$ years of age (mean, 23\%).

To examine the prognostic significance of PDGF- $\alpha$ receptor and PDGF-AA, the patients were divided into a group with high expression (PDGF- $\alpha$ receptor, $>34 \%$; PDGF-AA, $>21 \%$ ) and a group with low expression (PDGF- $\alpha$ receptor, $<34 \%$; PDGF-AA, $>21 \%$ ), based on the mean expression of these two proteins (see above). Univariate analysis revealed a significant shorter disease-free survival for patients with high PDGF-AA expression $(P=.0415$, log-rank test). The 5-year disease-free survival rate was $21.22 \%$ in the group with high expression compared with $42.72 \%$ in the group with low expression (Fig. 2A). For PDGF- $\alpha$ receptor expression, disease-free survival values failed to be statistically significant although a trend was obvious $(P=.0627$, log-rank test; Fig. 2B). Neither PDGF-AA nor PDGF- $\alpha$ receptor expression showed a significant influence on overall survival $(P>.05$, log-rank test), although the 5 -year survival rate was $46.49 \%$ in the group with high PDGF-AA expression compared with $76.65 \%$ in the group with low expression, and mean overall survival time was 5 years $(\mathrm{SD}, 0.75)$ in the first group compared with 6.9 years (SD, 0.56) in the second group. Univariate analysis also revealed a significant shorter disease-free survival for patients with tumors located in the trunk compared with those who had tumors in the upper or lower extremities $(P=.0118$, log-rank test).

In multivariate analysis of disease-free survival (Cox regression) comprising PDGF-AA expression, tumor location, tumor extension, and patient's age,
PDGF-AA expression ( $P=.021$; relative risk of 2.734), as well as tumor location $(P=.002$; relative risk of 2.472 for tumors located in the trunk) remained independent prognostic markers. Table 1 summarizes the results of univariate and multivariate analysis.

\section{DISCUSSION}

In this study, PDGF-AA and PDGF- $\alpha$ receptor expression was detected in a wide range of highly malignant human osteosarcomas, and the correlation between ligand and receptor was confirmed that had already been detected in our previous study in a smaller number of osteosarcoma specimens (11). The coordinate expression of these proteins suggests a functional autocrine and/or paracrine stimulation loop that promotes tumor growth. Furthermore, we correlated the protein expression with disease-free and overall survival data to elucidate the significance of these proteins as prognostic marker for osteosarcoma patients. Tumor progression correlated with high PDGF-AA expression, and in multivariate analysis, PDGF-AA remained an independent prognostic marker.

These results suggest that PDGF-AA expression could be useful as a pretherapeutic marker of prognosis. Therefore, immunohistochemical evaluation of PDGF-AA expression in biopsy material before chemotherapy or surgical treatment would help to identify tumors with high metastatic capability. These patients could be treated individually with more aggressive regimes.

\section{A}

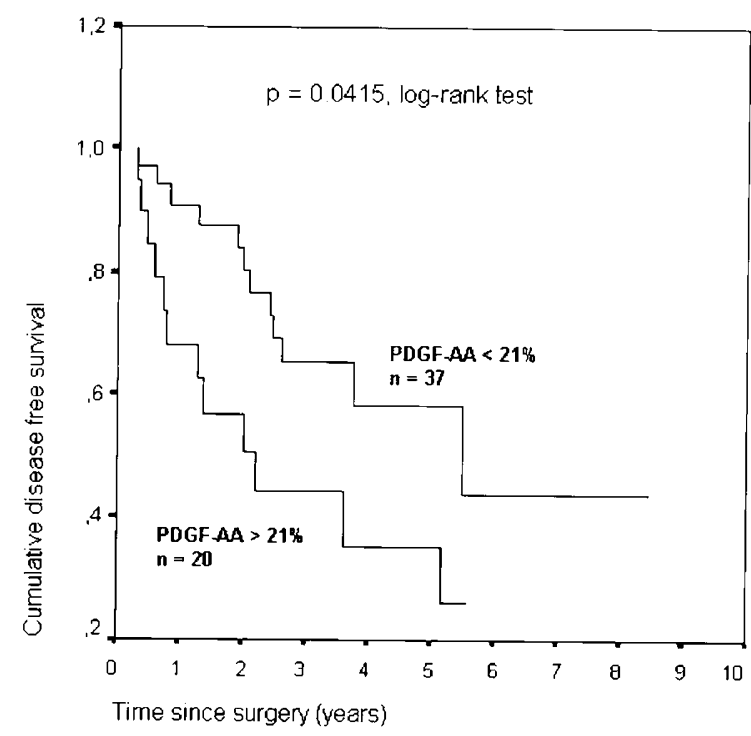

B

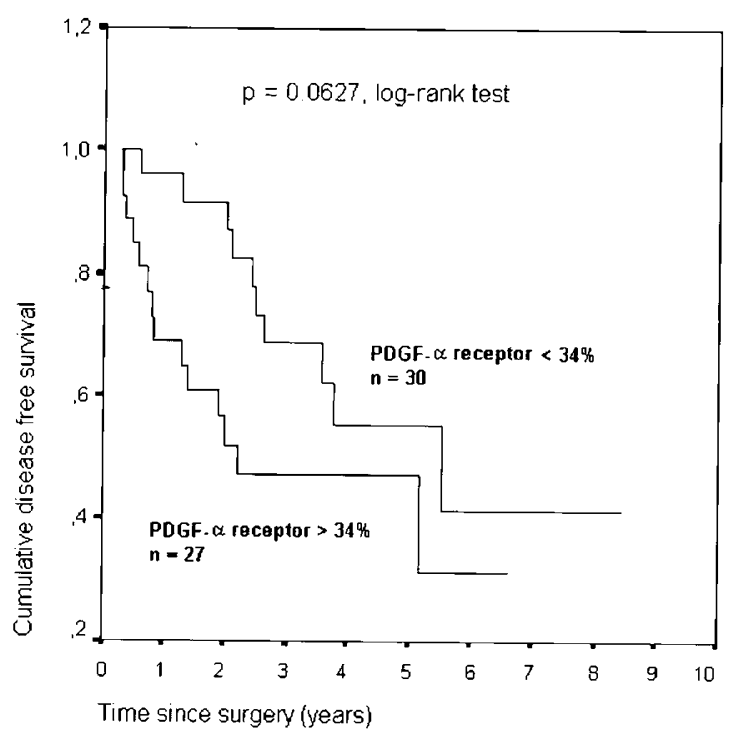

FIGURE 2. Disease-free survival of osteosarcoma patients relative to PDGF-AA expression. Patients with high expression of PDGF-AA ( $>21 \%$ of the tumor cells) had a significantly shorter disease-free survival (A). Patients with high expression of PDGF- $\alpha$ receptor ( $>34 \%$ of the tumor cells) show a clear tendency towards shorter disease-free survival, but comparison did not reach the level of statistical significance (B). 
TABLE 1. Disease-Free Survival Analysis

\begin{tabular}{lccc}
\hline \multirow{2}{*}{ Parameter } & $\begin{array}{c}\text { Univariate Analysis: } \\
P \text { Value }\end{array}$ & \multicolumn{2}{c}{ Multivariate Analysis } \\
\cline { 3 - 4 } & 0.0415 & $P$ Value & Relative Risk \\
\hline PDGF-AA & 0.866 & 0.021 & 2.734 \\
Age & 0.0118 & 0.405 & - \\
Location & 0.6629 & 0.002 & 2.472 \\
Extension & & 0.616 & - \\
\hline
\end{tabular}

On the other hand, the PDGF autocrine and/or paracrine stimulation loop might represent a novel therapeutic target itself by blocking the receptorligand interaction that inhibits receptor autophosphorylation, intracellular signal transduction, and finally the cellular effects of PDGF-AA. Different PDGF antagonists have already been developed, and the evaluation of their clinical effects in different animal models and in clinical trials is currently a main focus of many studies. In animal models, for example, the platelet-derived growth factor-binding molecule GFB-111 prevented receptor autophosphorylation, and GFB-111 treatment of nude mice bearing human tumors resulted in significant inhibition of tumor growth and angiogenesis (15). Other designed molecules directly inhibit the tyrosine kinase receptor $(16,17)$. Clinical studies comprised patients with hormone-refractory prostate cancer (18) as well as patients with solid tumors of different organs such as lung, colon, kidney, or soft tissue (19). Tyrosine kinase inhibitor imatinib (STI571) caused tumor regression in a patient with metastatic gastrointestinal stromal tumor (20), and the effect of this agent in patients with mesothelioma will be tested in a phase II trial (21).

A question that cannot be answered by immunohistochemistry is related to molecular changes that might contribute to protein overexpression. Studies concentrating on this subject were mainly done on neural tissue. In anaplastic oligodendrogliomas (22), for example, or in multiform glioblastomas (23), an amplification of the PDGF- $\alpha$ gene was found contributing to overexpression of the protein. Especially in neural tumor tissue, the coordinate expression of PDGFs and PDGF-receptors is well documented (22-25), and higher PDGF-AA expression levels can be found in advanced neuroblastoma tumor stages (26).

In one of our previous studies, we found high PDGF-AA and PDGF- $\alpha$ receptor expression in human chondrosarcomas compared with the case of benign enchondromas (27). In contrast to the results of the present study, high PDGF- $\alpha$ receptor expression was associated with adverse outcome for chondrosarcoma patients. For osteosarcoma patients, high PDGF- $\alpha$ receptor expression only showed a trend towards tumor progression. This difference might be explained by the fact that PDGF-AA expression is physiologically down- regulated in chondrocytes during bone formation, whereas osteoblasts express high levels of PDGF-AA in all stages of osteogenesis (10). Therefore, receptor-ligand interaction might be more dependent on the PDGF-AA homodimer in osteoblasts, as it is in cartilage cells.

Growth factors play a potential role in tumor growth and progression. In osteosarcoma, the search for stimulating proteins that exert their function by binding to their receptors located on tumor cells is not limited to PDGFs. VEGF isoforms and their receptors have been demonstrated in human osteosarcoma in vivo, and detection of special isoforms have been found to be of prognostic value (4). Ligand and receptor co-expression for the hepatocyte growth factor and receptor have been demonstrated in human osteosarcomas, suggesting a paracrine or autocrine mechanism of growth stimulation (28). Insulin-like growth factors have also been found to stimulate osteosarcoma growth by binding to their receptors in vivo and in vitro $(29,30)$.

In summary, our study documents co-expression of PDGF-AA and PDGF- $\alpha$ receptor in human osteosarcoma cells, suggesting a functional autocrine and/or paracrine loop of growth stimulation. Furthermore, PDGF-AA expression is associated with tumor progression. Therefore, the immunohistochemical evaluation of the protein expression could be used as a prognostic parameter for osteosarcoma patients, and it may be considered as a target for novel therapeutic strategies.

\section{REFERENCES}

1. Dorfman HD, Czerniak B. Osteosarcoma. In: Dorfman HD, Czerniak B, editors. Bone tumors. 1st ed. St. Louis, MO: Mosby; 1998. p. 128-252.

2. Wada T, Isu K, Takeda N, Usui M, Ishii S, Yamawaki S. A preliminary report of neoadjuvant chemotherapy NSH-7 in osteosarcoma: preoperative salvage chemotherapy based on clinical tumor response and the use of granulocyte colonystimulating factor. Oncology 1996;53:221-7.

3. Kaya M, Wada T, Akatsuka T, Akatsuka T, Kawaguchi S, Nagoya S, et al. Vascular endothelial growth factor expression in untreated osteosarcoma is predictive of pulmonary metastasis and poor prognosis. Clin Cancer Res 2000;6:572-7.

4. Lee HY, Tokunaga T, Oshika Y, Suto R, Yanagisawa K, Tomisawa M, et al. Cell-retained isoforms of vascular endothelial growth factor (VEGF) are correlated with poor prognosis in osteosarcoma. Eur J Cancer 1999;35:1089-93.

5. Dvorak HF, Brown LF, Detmar M, Dvorak AM. Vascular permeability factor/vascular endothelial growth factor, microvascular permeability, and angiogenesis. Am J Pathol 1995;146:1029-39.

6. Betsholtz C, Karlsson L, Lindahl P. Developmental roles of platelet-derived growth factors. Bioessays 2001;23:494-507.

7. Westermark B, Heldin CH. Platelet-derived growth factor. Acta Oncol 1993;32:101-5.

8. Seifert RA, Hart CE, Phillips PE, Forstrom JW, Ross R, Murray MJ, et al. Two different subunits associate to create isoform- 
specific platelet-derived growth factor receptors. J Biol Chem 1989;264:8771-8.

9. Andrew JG, Hoyland JA, Freemont AJ, Marsh DR. Plateletderived growth factor expression in normally healing human fractures. Bone 1995;16:455-60.

10. Horner A, Bord S, Kemp P, Grainger D, Compston JE. Distribution of platelet-derived growth factor (PDGF) A chain mRNA, protein, and PDGF-alpha receptor in rapidly forming human bone. Bone 1996;19:353-62.

11. Sulzbacher I, Träxler $M$, Mosberger I, Lang S, Chott A. Platelet-derived growth factor-AA and $-\alpha$ receptor expression suggests an autocrine and/or paracrine loop in osteosarcoma. Mod Pathol 2000;13:632-7.

12. Kaplan EL, Meier P. Nonparametric estimation from incomplete observations. J Am Stat Assoc 1985;53:457-81.

13. Ozaki T, Flege S, Liljenqvist U, Hillmann A, Delling G, SalzerKuntschik M, et al. Osteosarcoma of the spine: experience of the cooperative osteosarcoma study group. Cancer 2002;94: 1069-77.

14. Salzer-Kuntschik M, Brand G, Delling G. Determination of the degree of morphological regression following chemotherapy in malignant bone tumors. Pathologe 1983;4:13541.

15. Blaskovich MA, Lin Q, Delarue FL, Sun J, Park HS, Coppola D, et al. Design of GFB-111, a platelet-derived growth factor binding molecule with antiangiogenic and anticancer activity against human tumors in mice. Nat Biotechnol 2000;18: 1065-70.

16. Laird AD, Vajkoczy P, Shawver LK, Thurnher A, Liang C, Mohammadi M, et al. SU 6668 is a potent antiangiogenic and antitumor agent that induces regression of established tumors. Cancer Res 2000;60:4152-60.

17. Shawver LK, Schwartz DP, Mann E, Chen H, Tsai J, Chu L, et $a l$. Inhibition of platelet-derived growth factor-mediated signal transduction and tumor growth by $N$-[4(trifluoromethyl)-phenyl]5-methylisooxazole-4carboxamide. Clin Cancer Res 1997;3:1167-77.

18. Ko YJ, Small EJ, Kabbinavar F, Chachoua A, Taneja S, Reese D, et al. A multi-institutional phase ii study of SU 101, a platelet-derived growth factor receptor inhibitor, for patients with hormone-refractory prostate cancer. Clin Cancer Res 2001;7:800-5.

19. Echhardt JR, Rizzo J, Sweeney KR, Cropp G, Baker SD, Kraynak MA, et al. Phase I and pharmacological study of the tyrosine kinase inhibitor SU101 in patients with advanced solid tumors. J Clin Oncol 1999;17:1095-104.

20. Joensuu H, Roberts P, Sarlomo-Rikala M, Andersson LC, Tervahartiala P, Tuveson D. Effect of the tyrosine kinase inhibitor STI571 in a patient with metastatic gastrointestinal stromal tumor. N Engl J Med 2001;344:1052-6.

21. Nowak AK, Lake RA, Kindler HL, Robinson BWS. New approaches for mesothelioma: biologics, vaccines, gene therapy, and other novel agents. Semin Oncol 2002;29:82-96.

22. Smith JS, Wang XY, Qian J, Hosek SM, Scheithauer BW, Jenkins RB, et al. Amplification of the platelet-derived growth receptor-A (PDGFRA) gene occurs in oligodendrogliomas with grade VI anaplastic features. J Neuropathol Exp Neurol 2000;59:495-503.

23. Saxena A, Shriml LM, Dean M, Ali IU. Comparative molecular genetic profiles of anaplastic astrocytomas/glioblastomas multiforme and their subsequent recurrences. Oncogene 1999;18:1385-90.

24. Yang SY, Xu GM. Expression of PDGF and its receptor as well as their relationship to proliferating activity and apoptosis of meningiomas in human meningiomas. J Clin Neurosci 2001; 8:49-53.

25. Hermanson M, Funa K, Hartman M, Claesson-Welsh L, Heldin $\mathrm{CH}$, Westermark B, et al. Platelet-derived growth factor and its receptors in human glioma tissue: expression of messenger RNA and protein suggests the presence of autocrine and paracrine loops. Cancer Res 1992;52:3213-9.

26. Eggert A, Ikegaki N, Kwiatkowski J, Zhao H, Brodeur GM, Himelstein BP. High-level expression of angiogenic factors is associated with advanced tumor stage in human neuroblastomas. Clin Cancer Res 2000;6:1900-8.

27. Sulzbacher I, Birner P, Trieb K, Mühlbauer M, Lang S, Chott A. Platelet-derived growth factor- $\alpha$ receptor expression supports the growth of conventional chondrosarcoma and is associated with adverse outcome. Am J Surg Pathol 2002;25: $1520-7$

28. Ferracini R, Di-Renzo MF, Scotlandi K, Baldini N, Olivero M, Lollini $\mathrm{P}$, et al. The Met/HGF receptor is overexpressed in human osteosarcomas and is activated by either a paracrine or an autocrine circuit. Oncogene 1995;16:739-49.

29. Burrow S, Andrulis IL, Pollak M, Bell RS. Expression of insulin-like growth factor receptor, IGF-1, and IGF-2 in primary and metastatic osteosarcoma. J Surg Oncol 1998;69: 21-7.

30. Raile K, Hoflich A, Kessler U, Yang Y, Pfuender M, Blum $\mathrm{WF}$, et al. Human osteosarcoma (U-2 OS) cells express both insulin-like growth factor (IGF-I) receptors and insulin-like growth factor-II/mannose-6-phosphate (IGFII/M6P) receptors and synthesize IGF-II: autocrine growth stimulation by IGF-II via the IGF-I receptor. J Cell Physiol 1994;159:531-41. 